\title{
Non-invasive recording technologies for the study and conservation of prehistoric rock art: the Dolmen of Dombate
}

\author{
Natalia Cortón Noya \\ Fernando Carrera Ramírez \\ Patricia Mañana-Borrazás \\ Yolanda Seoane-Veiga
}

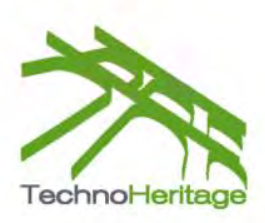

International Congress on

Science and Technology for the Conservation of Cultural Heritage 
The Dolmen of Dombate (Cabana de Bergantiños, A Coruña)
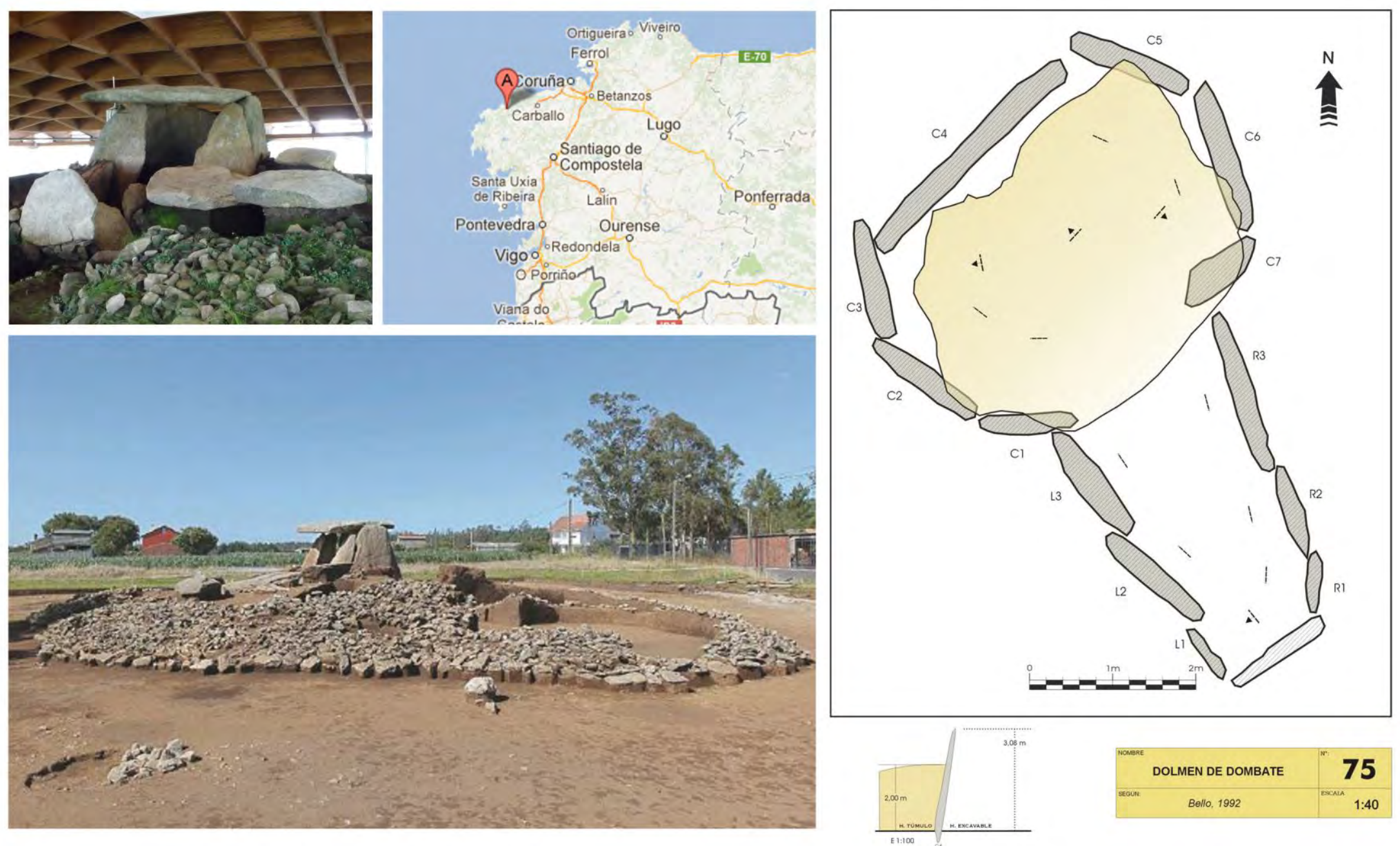

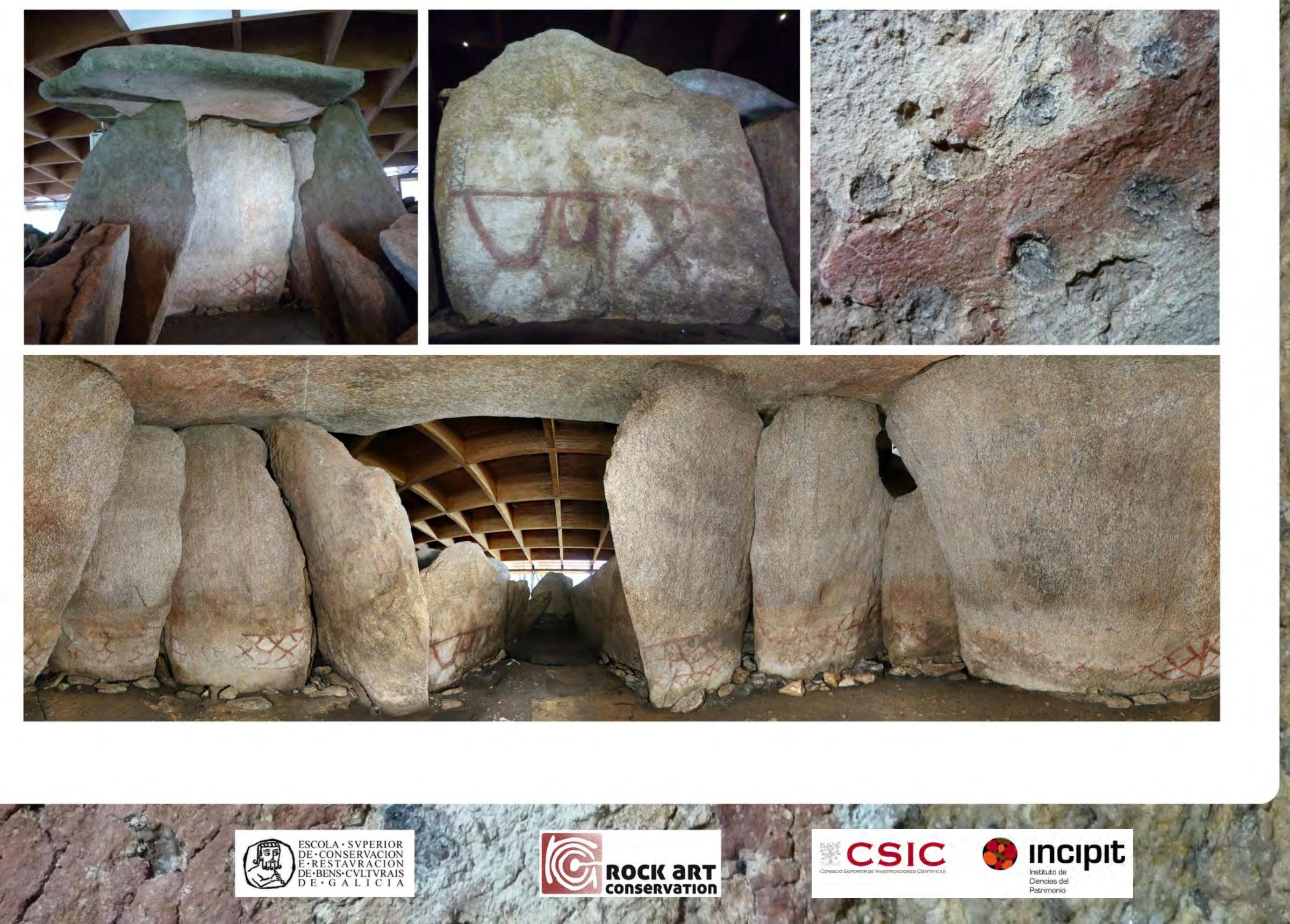


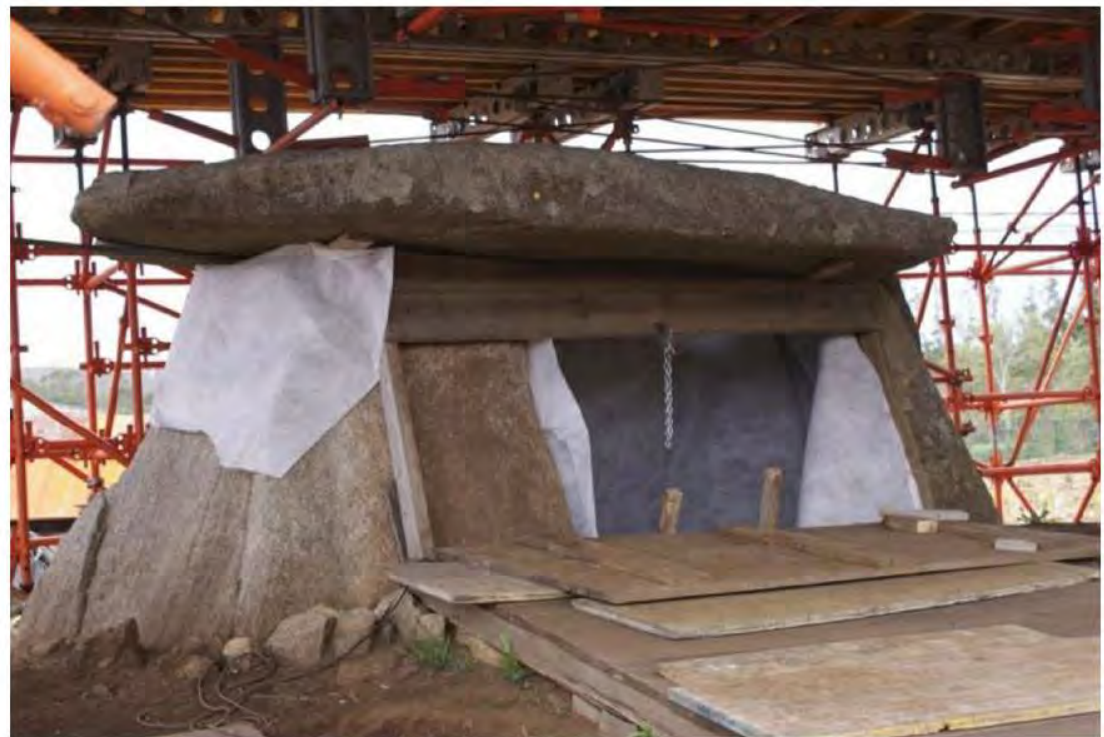

Provisional wooden cover

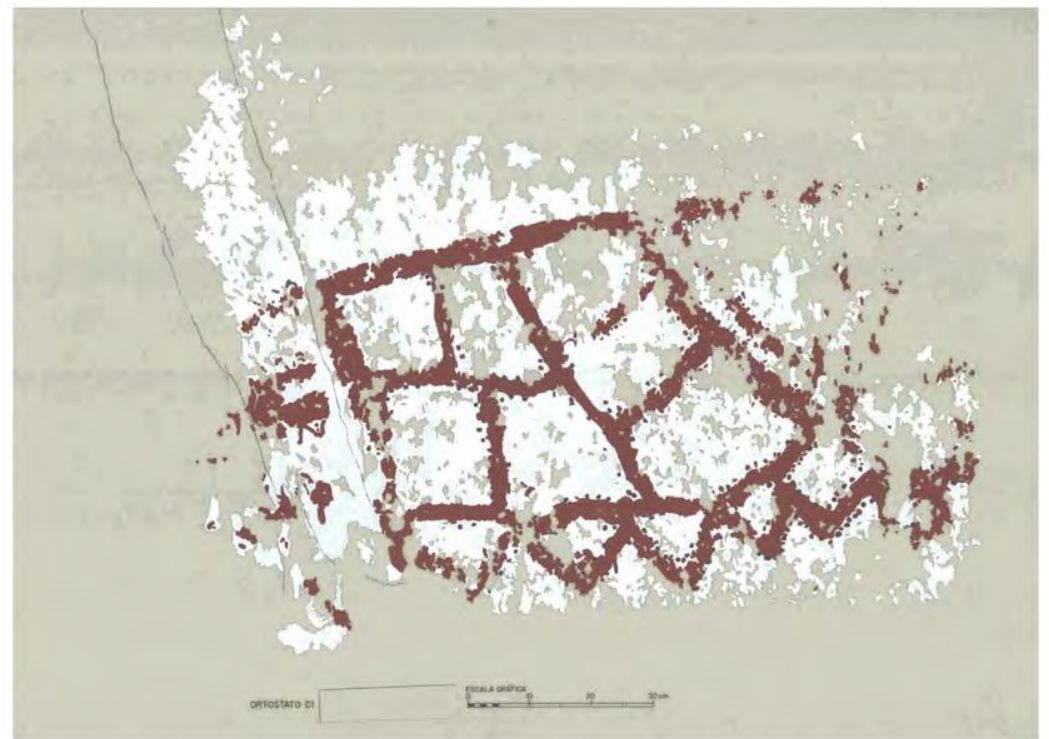

Recording of the art through direct tracing (César Méndez / Tomos S.L., 1994) 

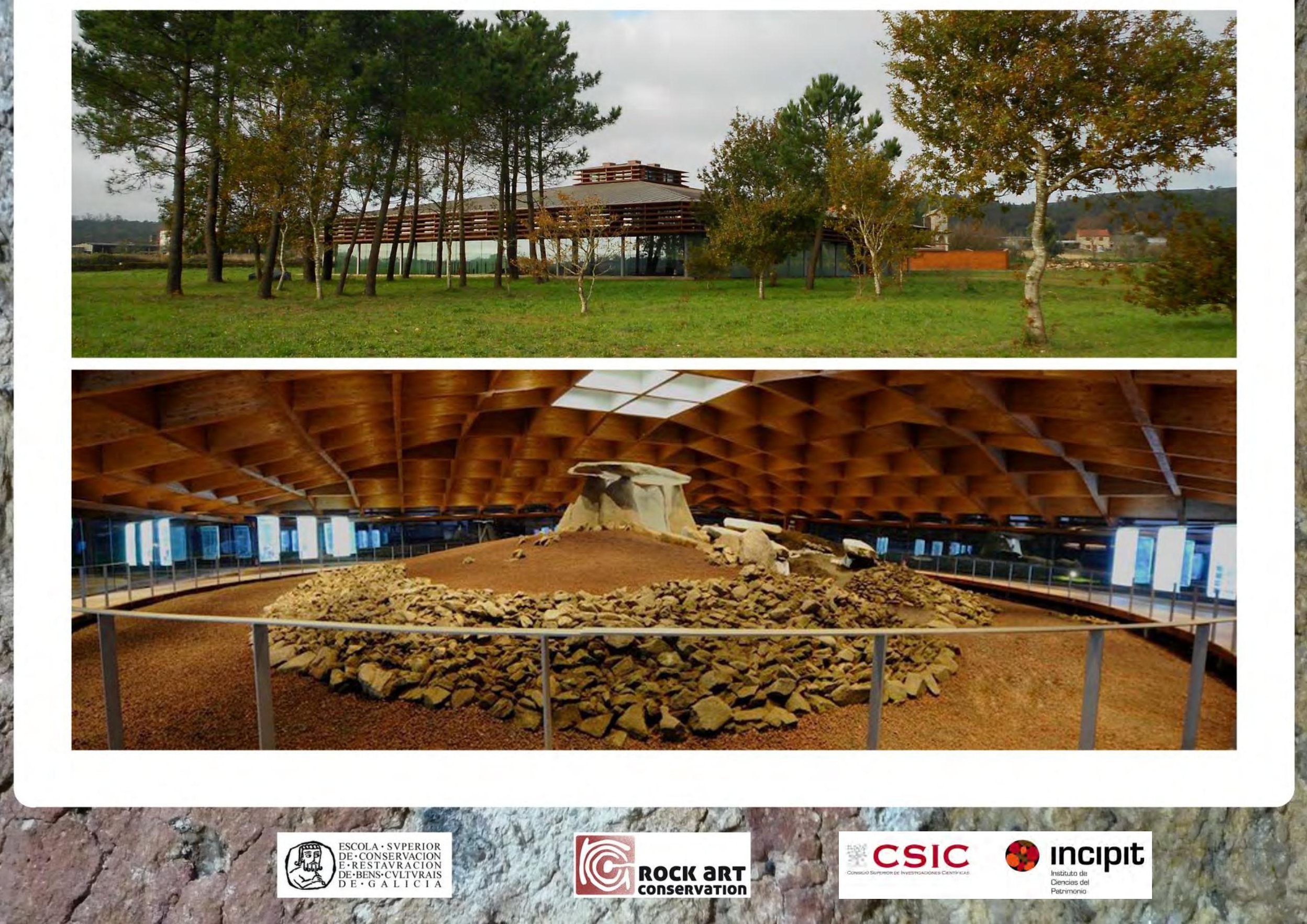


\section{Main objectives:}

- Obtaining a precise documentation of the preserved art (paintings and engravings)

- Verification of the state of the paintings before and after the works, so as to evaluate possible damages and alterations during the construction works.

- Application of indirect and non-invasive recording techniques
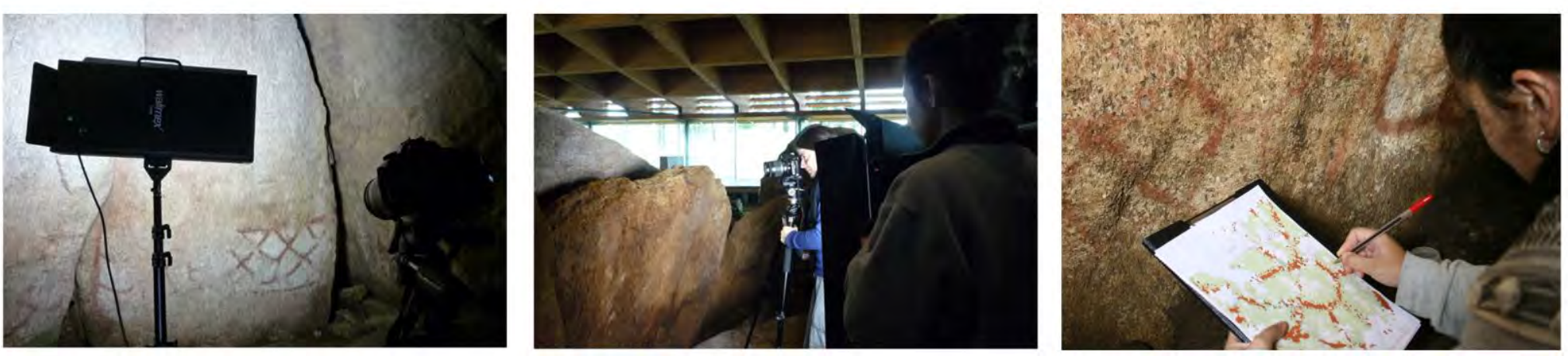


\section{Documentation of the site:}

- Photographic and video report

- Generation of a series of panoramic images (planar and full spherical)

- Photographic report of the state of preservation of the paintings before and after the cleaning treatments

- Generation of orthophotographs (close-range photogrammetry)

- Generation of orthophotographs and three-dimensional models (structured-light scanning)
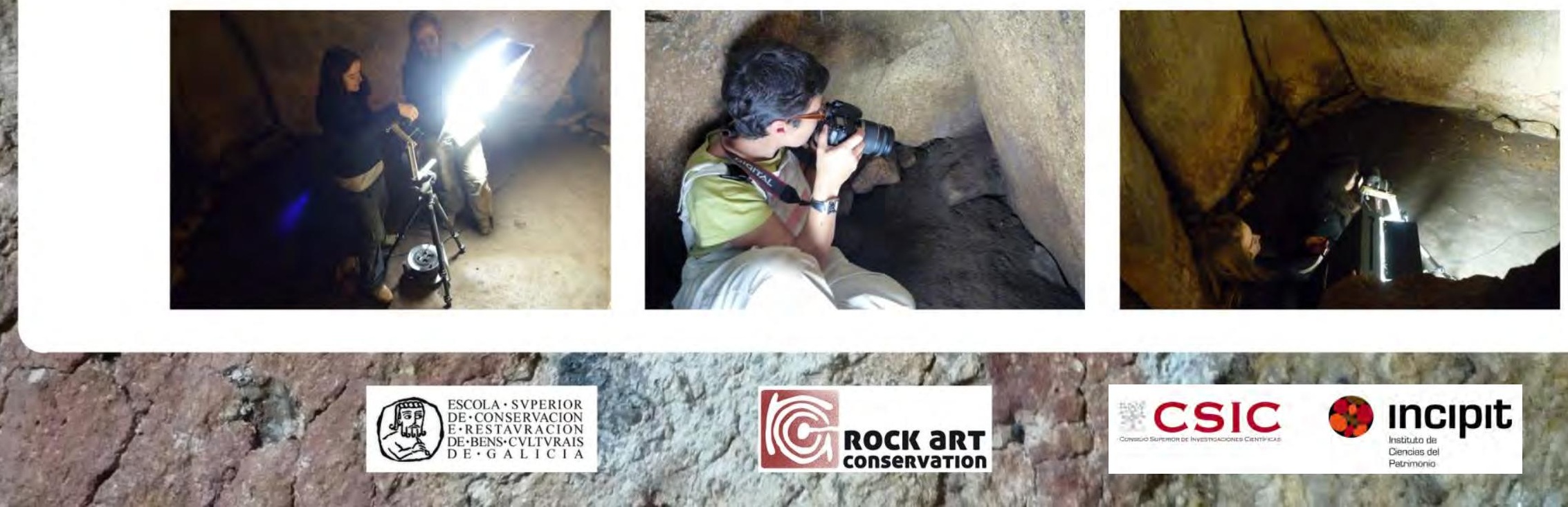


\section{Panoramic photography}
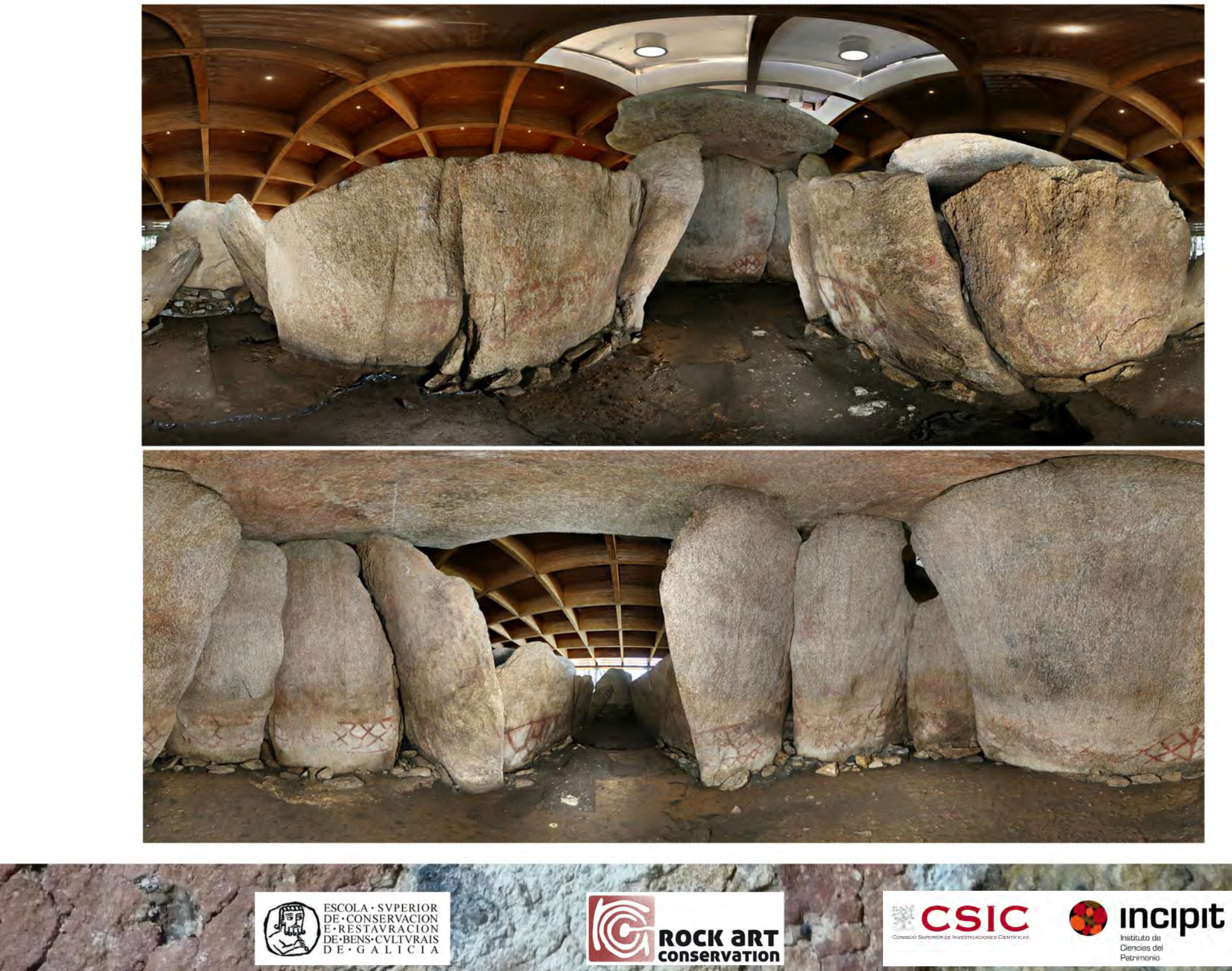

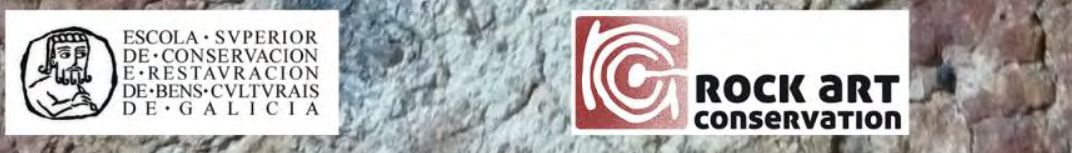
CSIC 
Photographic report of the state of preservation of the paintings

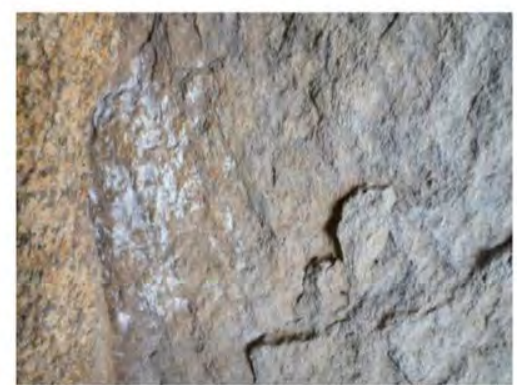

C7: Lichen

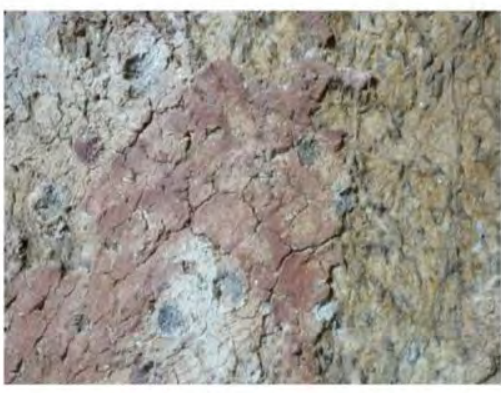

C1: Cracking

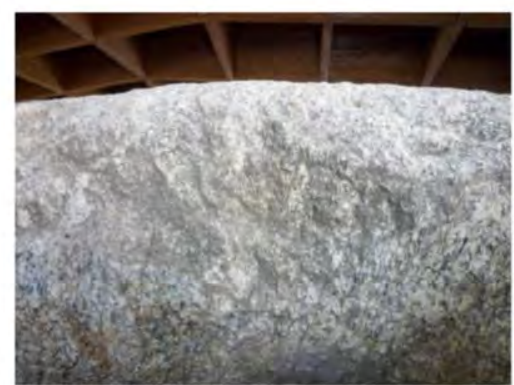

L1: Algae

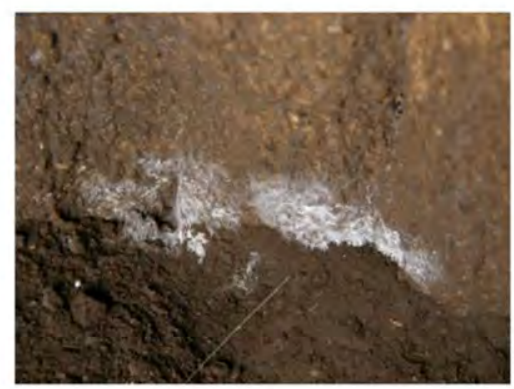

L2: Fungi

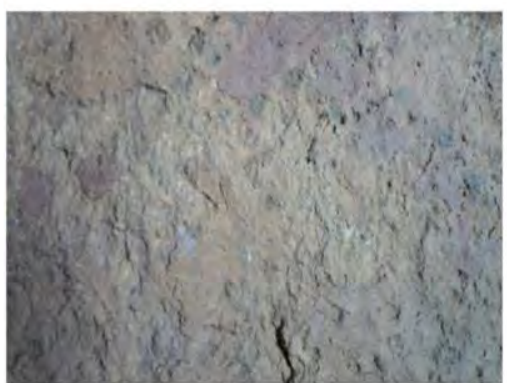

C6: Fungi

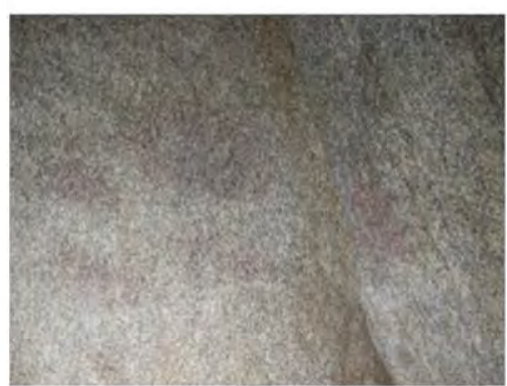

C1: Rubefaction

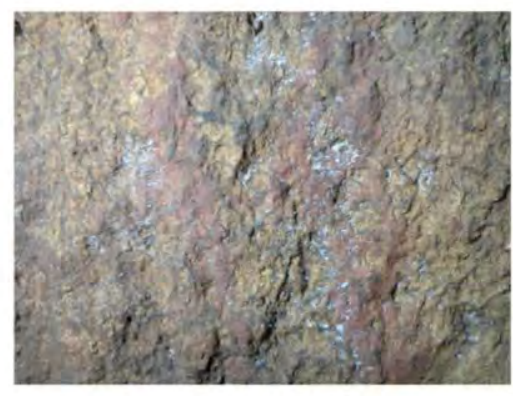

R2: Fungi

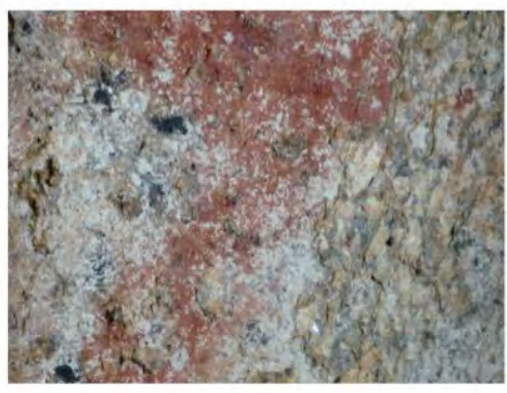

C5: Flaking 


\section{Detailed alteration maps of each of the orthostats}
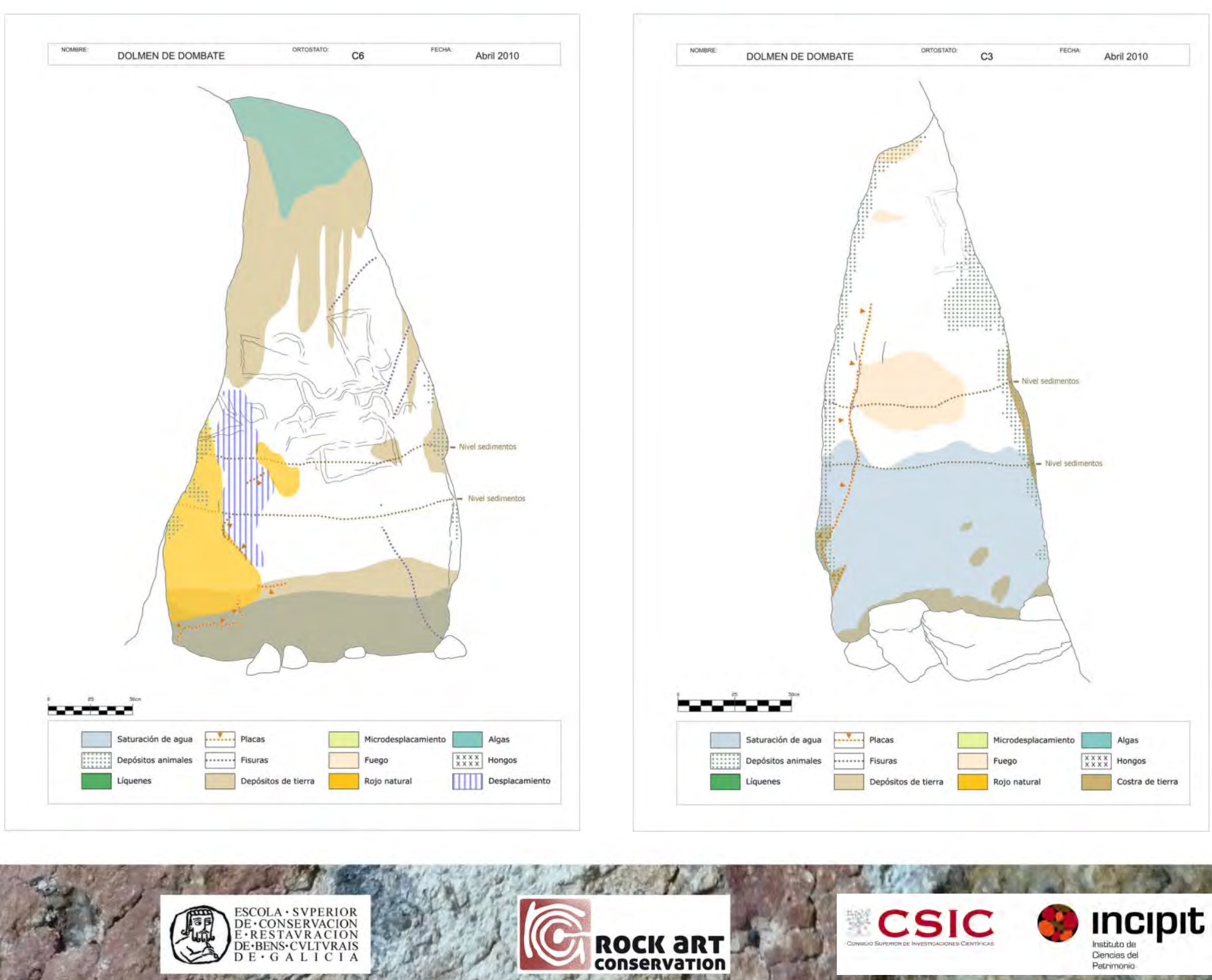

CSIC Incipit 


\section{Close-range photogrammetry \& Structured-light scanning}

- Obtaining a series of orthophotographs and 3D models of the orthostats

- Obtaining digital tracings of the paintings and engravings from the orthophotographs generated 
Close-range photogrammetry: generation of orthophotos

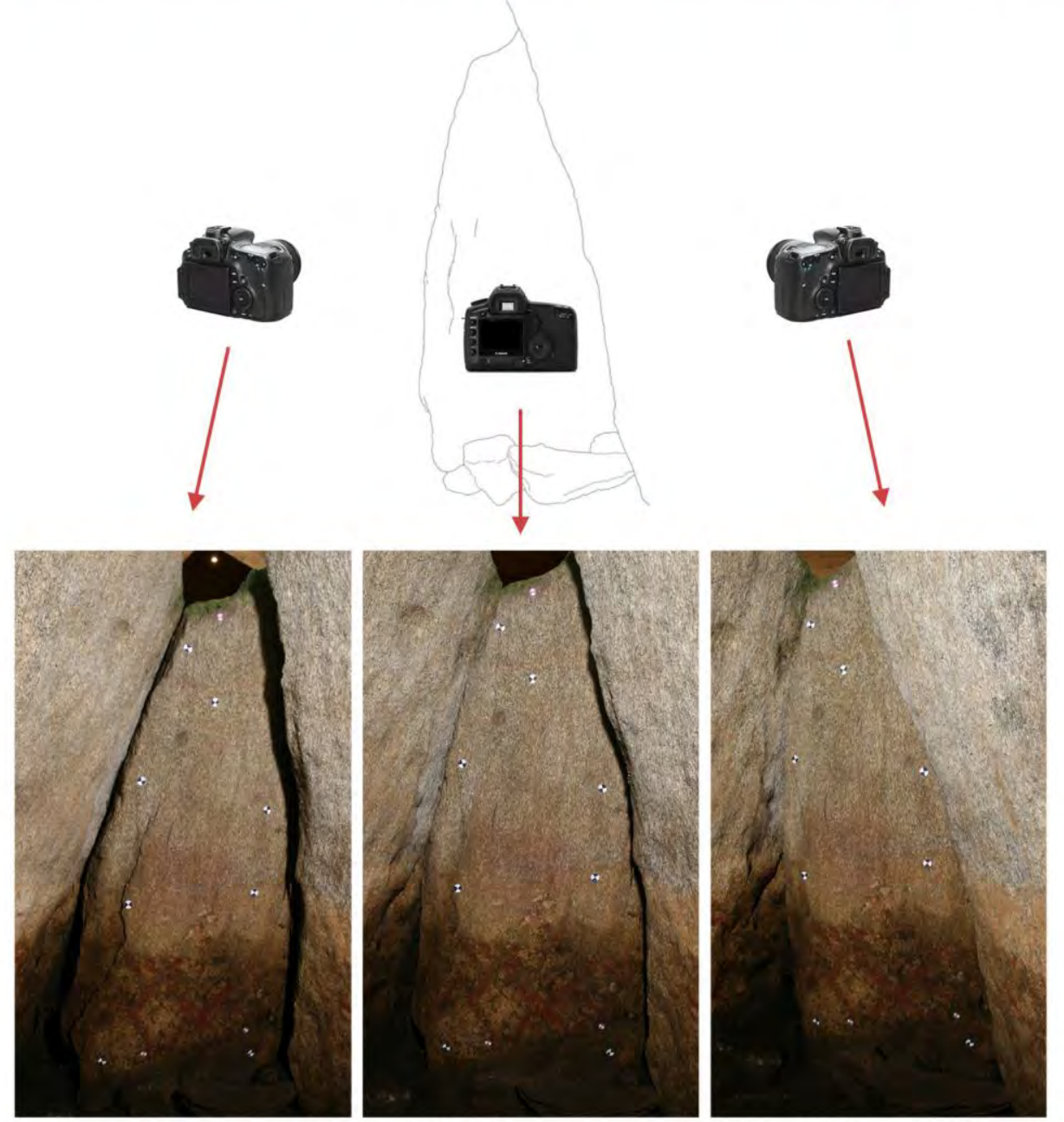

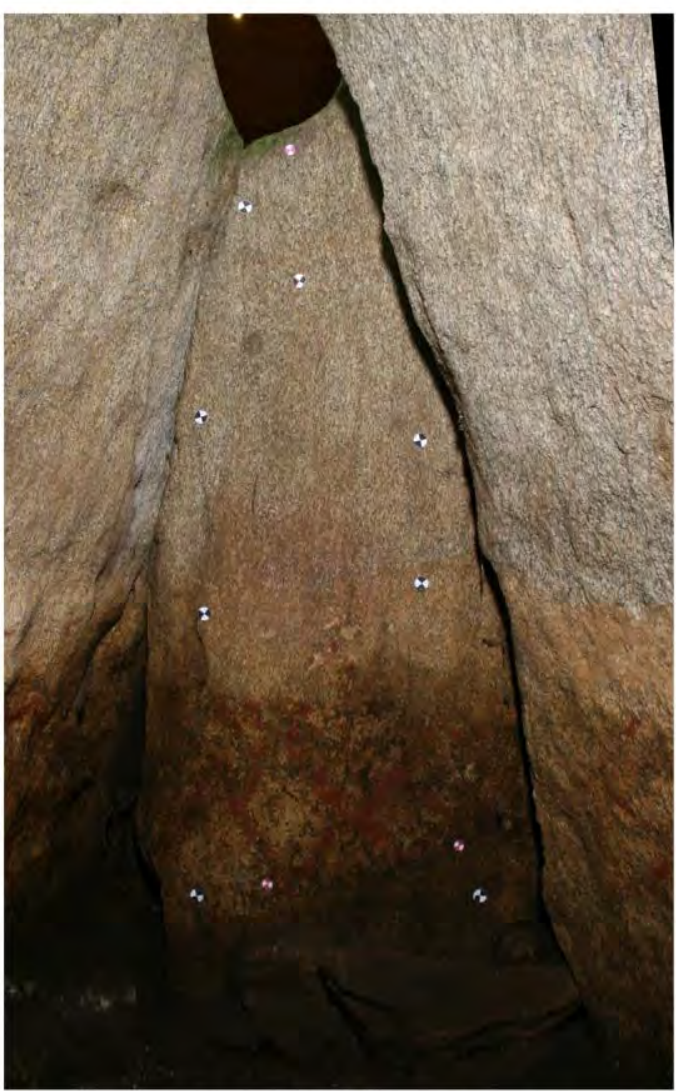

Final orthophoto

Photogrammetric restitution: necessary photographs

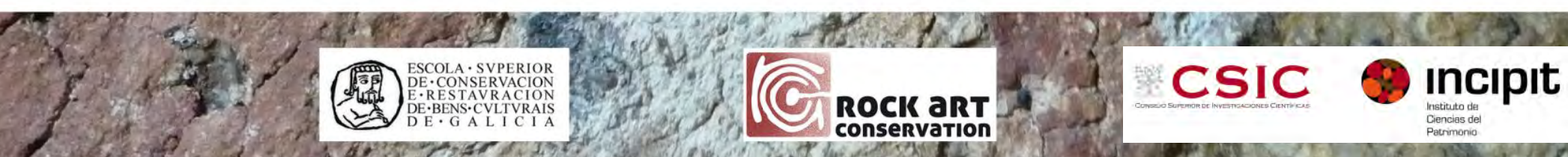


Close-range photogrammetry: recording of the orthostats

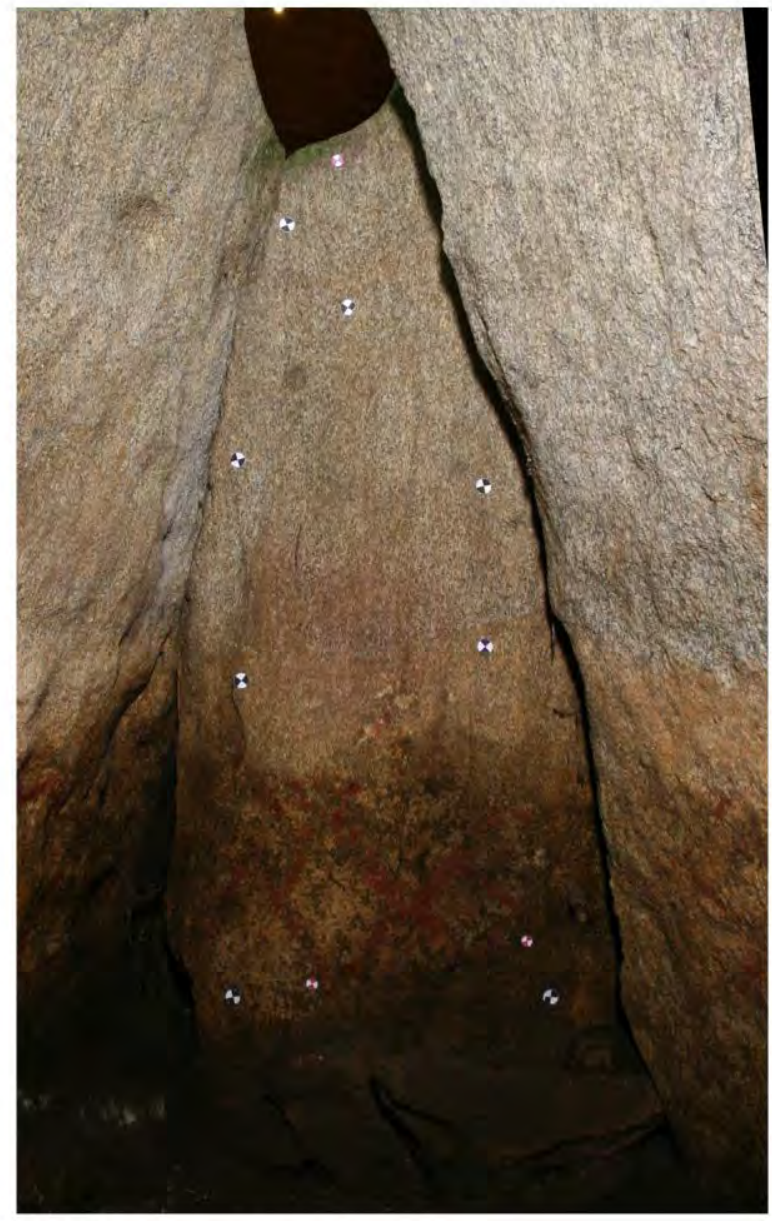

Orthophotography

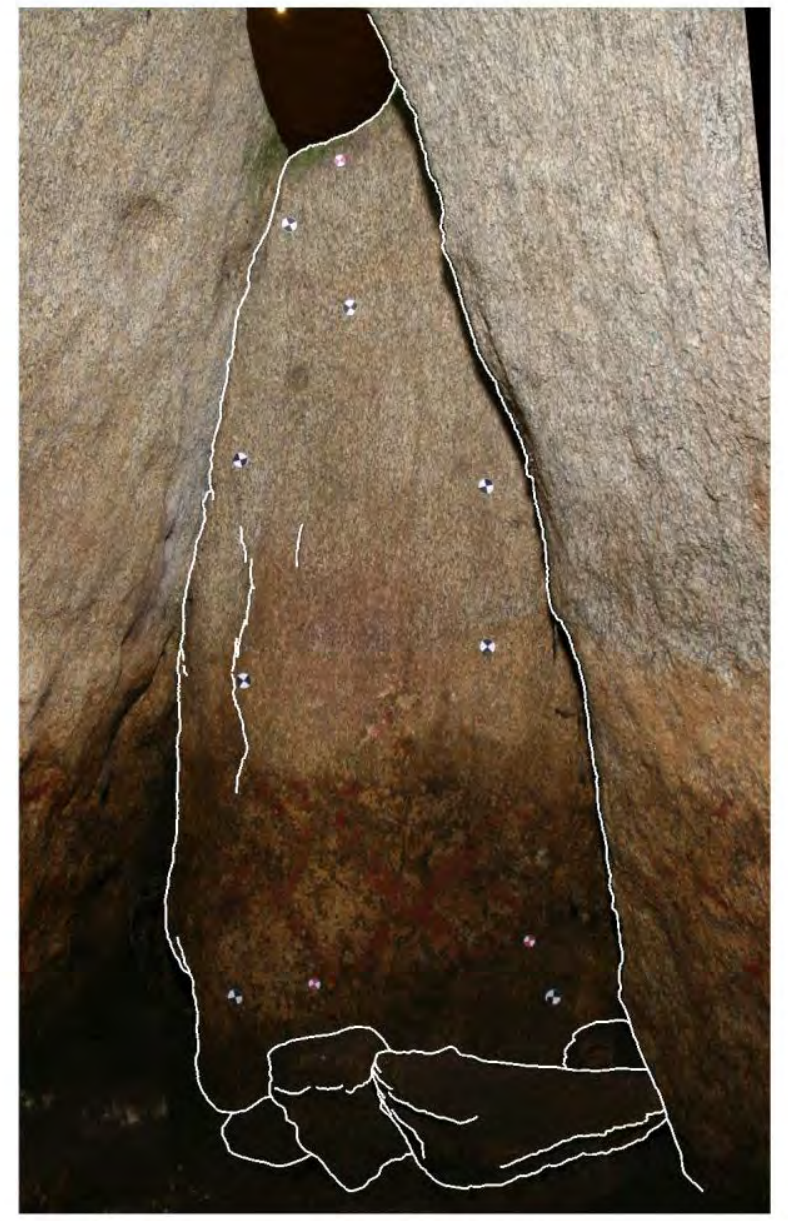

Digital tracing (AutoCAD)

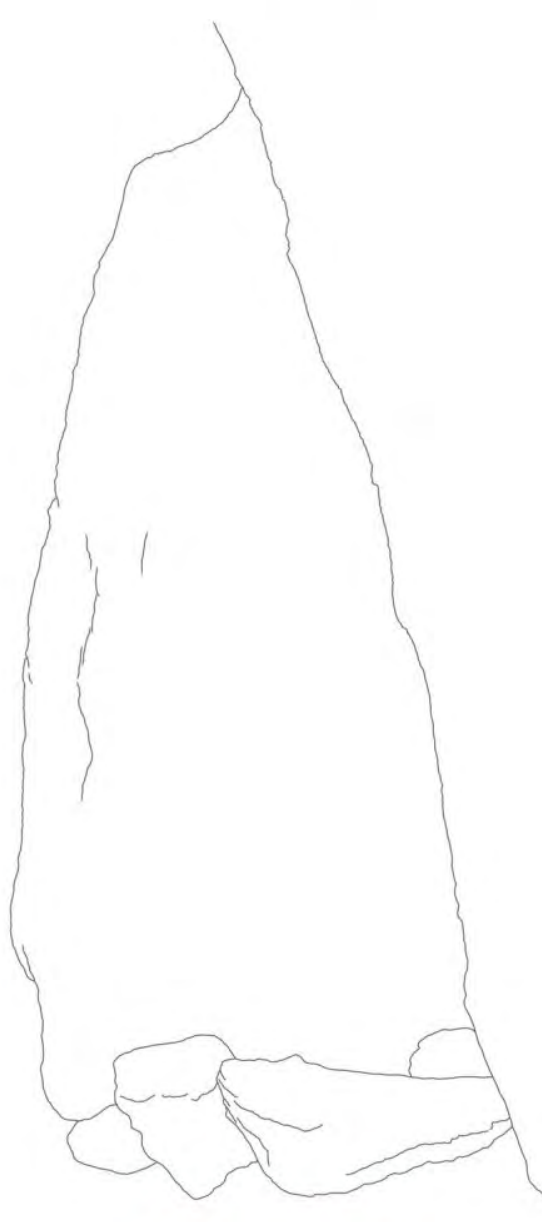

Resultant map 


\section{Close-range photogrammetry: recording of the paintings}
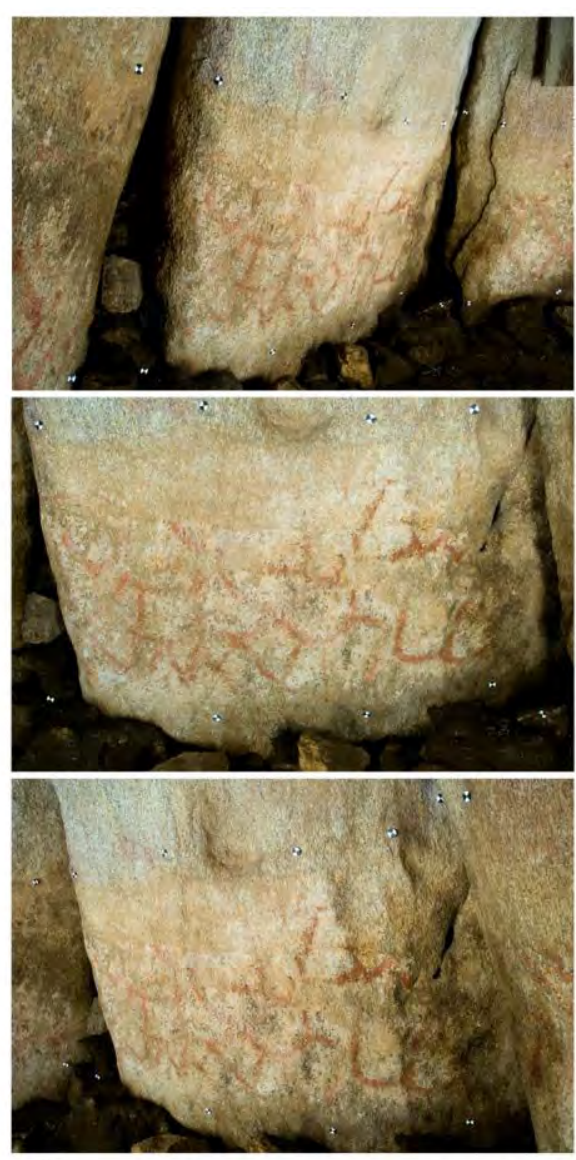

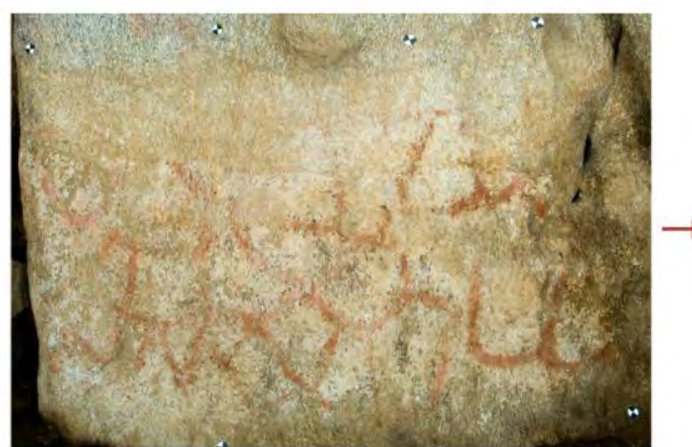

Orthophotography

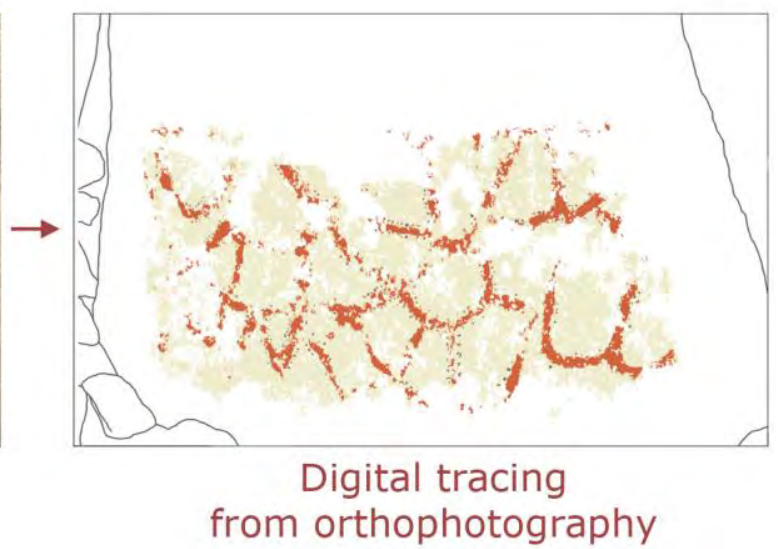

Photogrammetric restitution: necessary photographs 
Improving the visibility of the paintings in the images:

- By the use of polarising filters while taking photographs

- By the digital treatment of the orthophotographs generated with photogrammetry
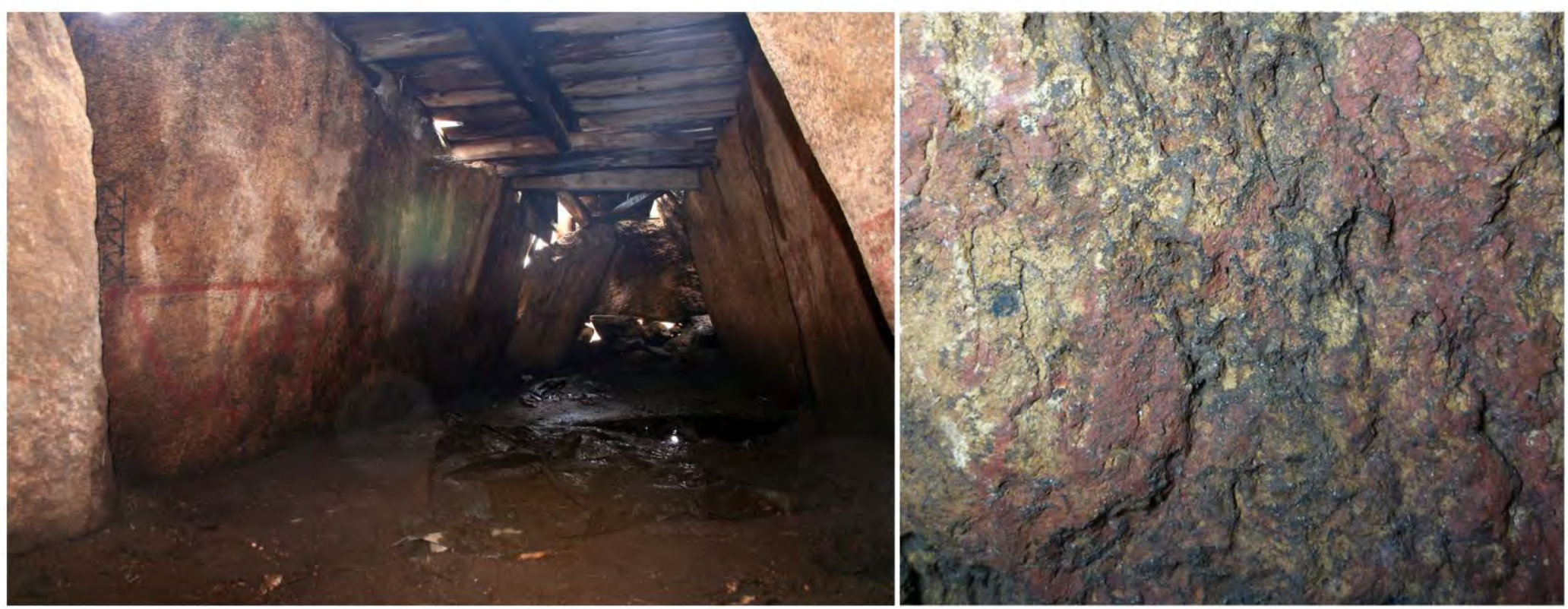
Digital treatment of orthophotographs:
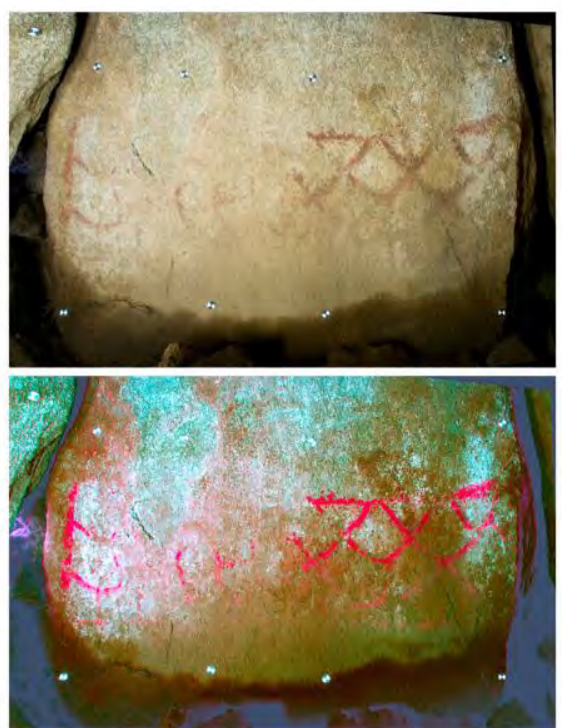

$+\quad$ Auxiliary materials

(detail and macro photography, orthophotographs obtained with structured-light scanning, comparison with previous direct tracings, first-hand on site

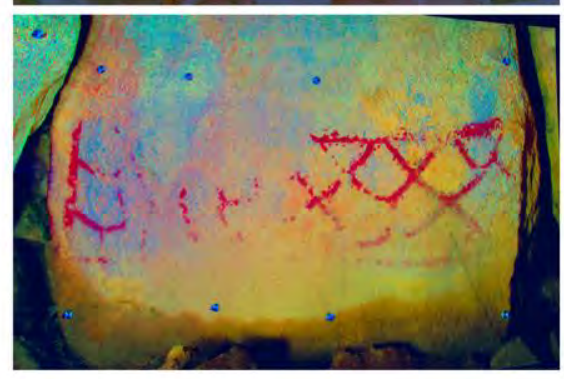
observations, etc.)

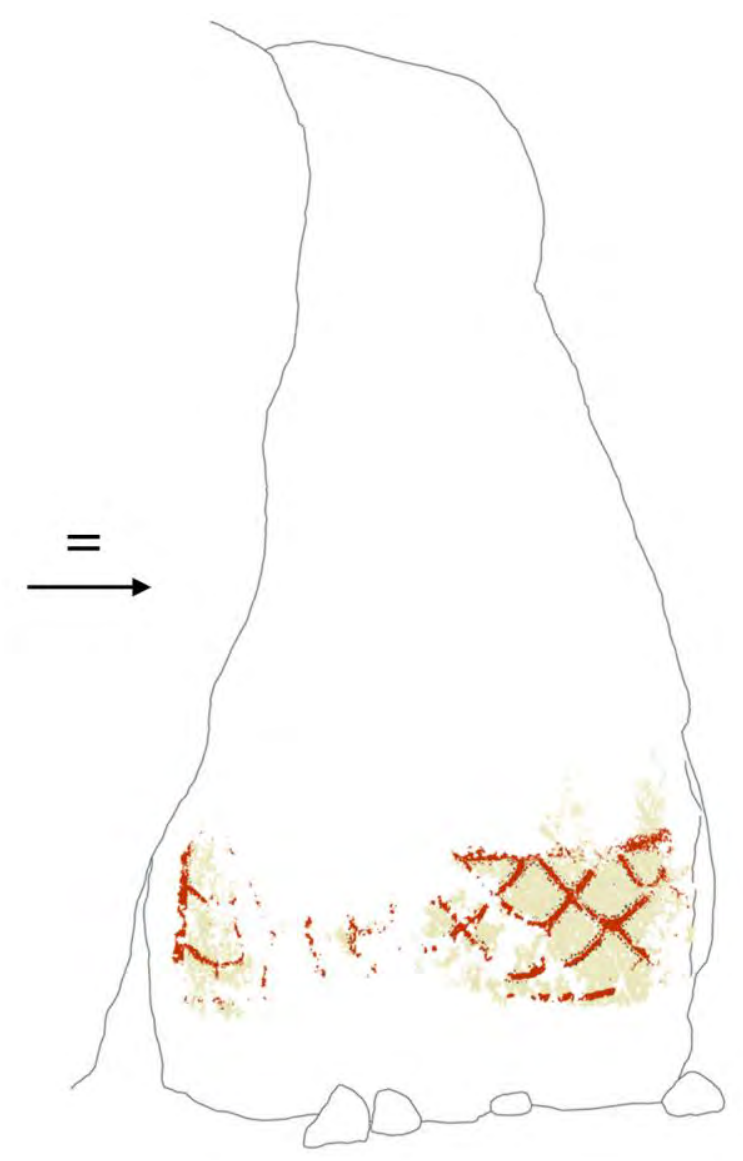


Close range photogrammetry: Recording of the engravings
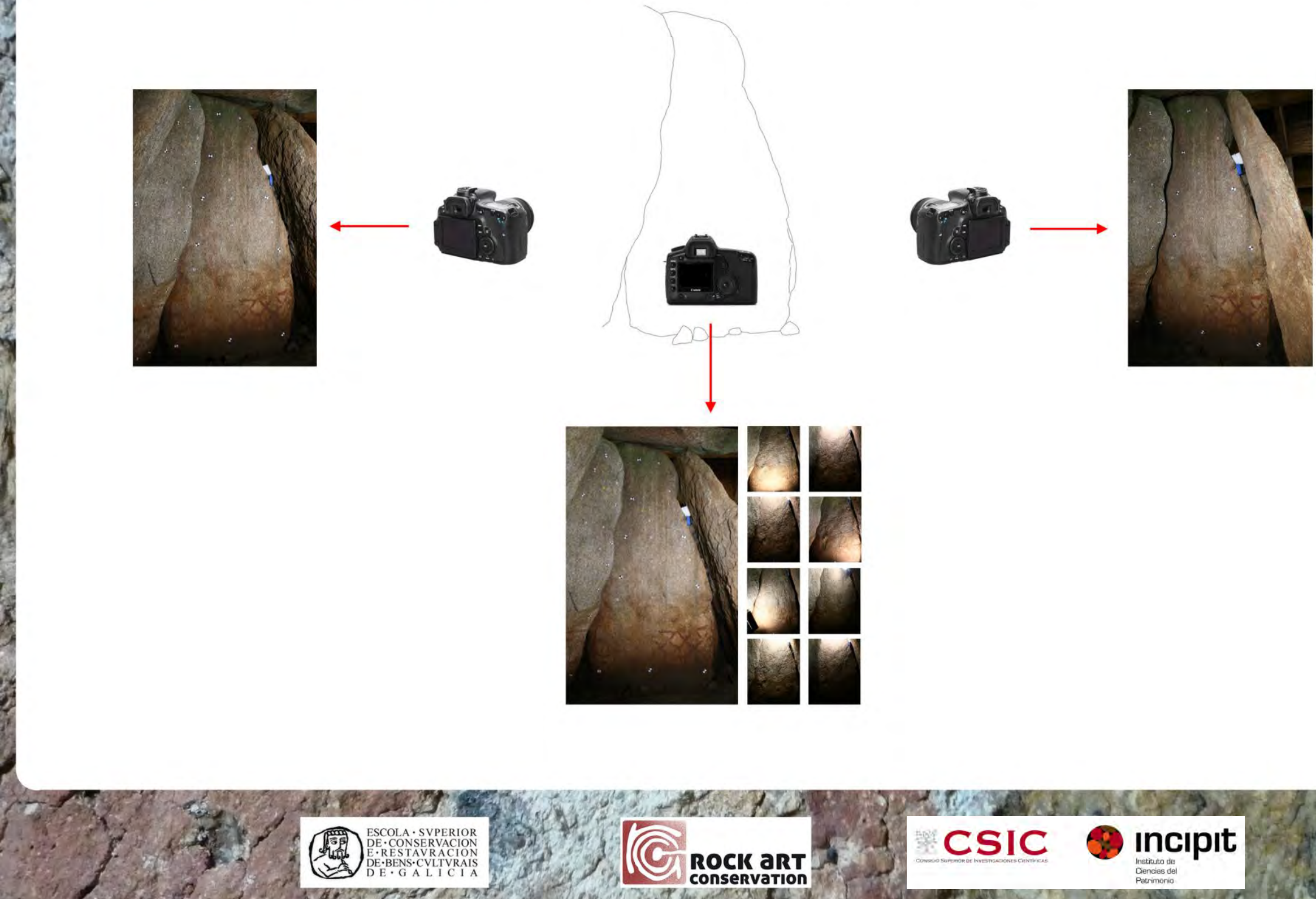

CSIC Incipit

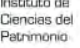


Close range photogrammetry: Recording of the engravings
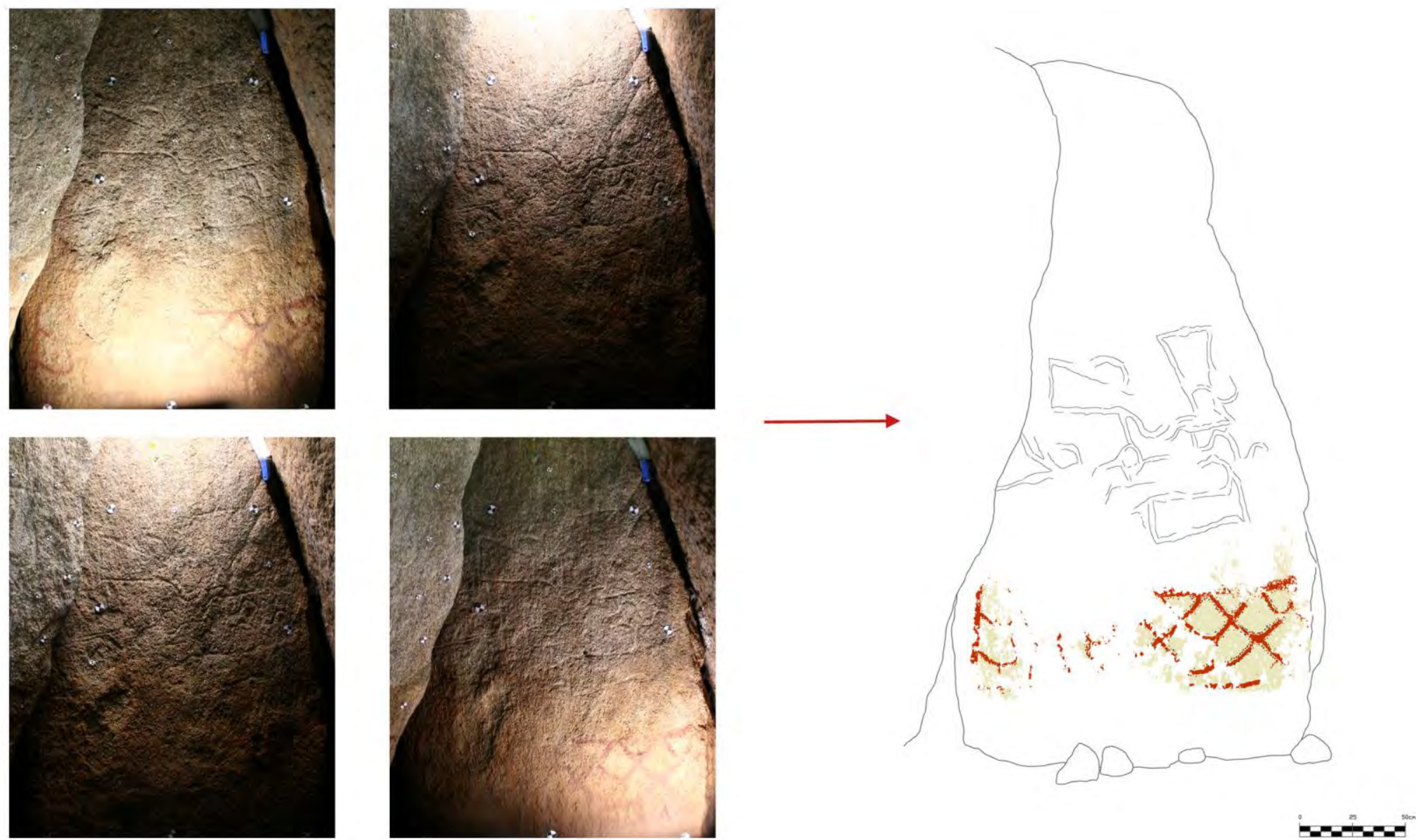


\section{Structured-light scanning}

- Nub3D Scanner (Sidio Advance model). Software Triple.

- The measurement technique is based on structured-light triangulation, being possible to capture in a single scanning up to to 1,4 million points
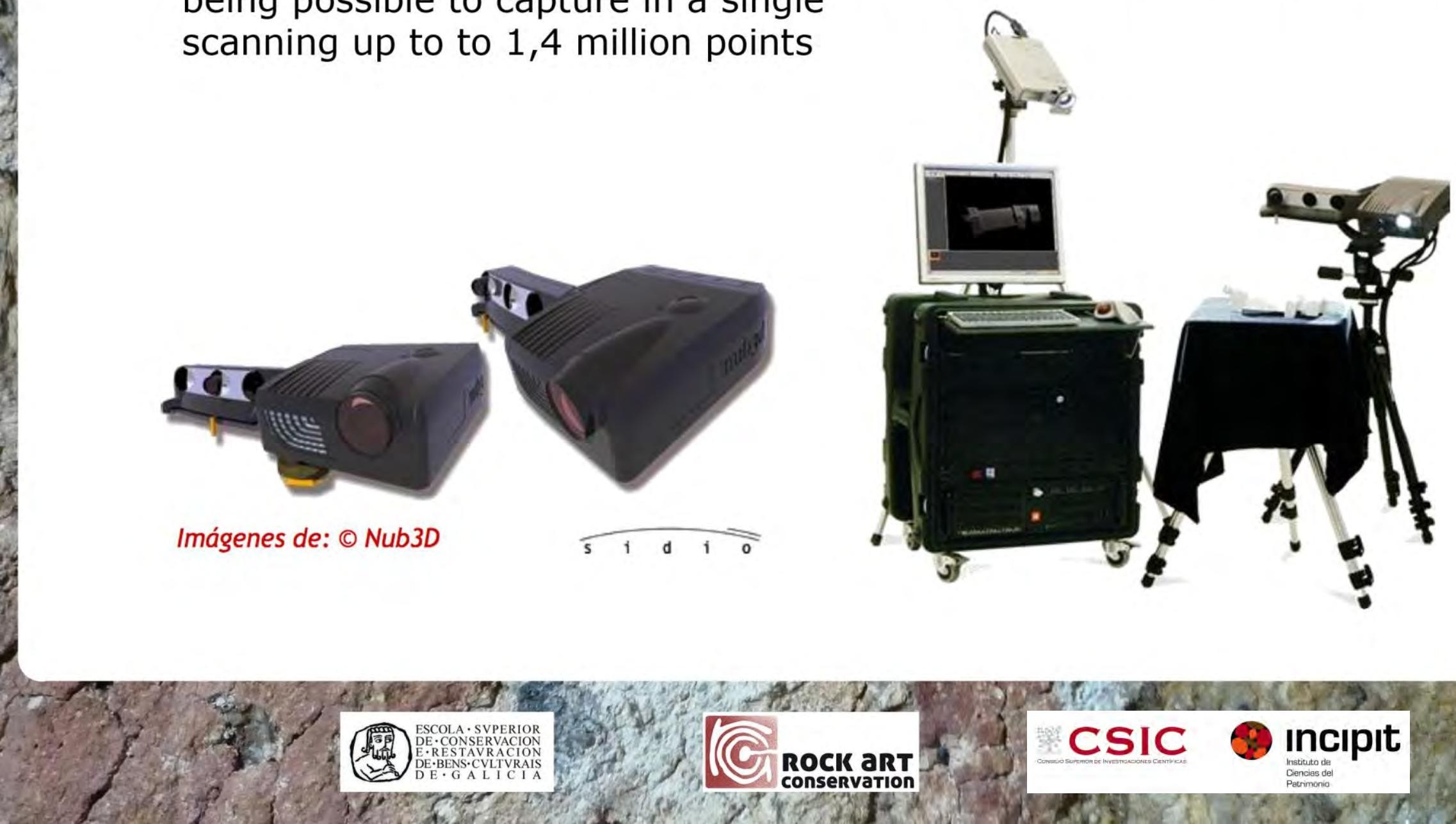
Structured-light scanning

- The scanner projects a pattern of parallel stripes onto the surface.

- It registers the geometrical distortion of this pattern due to the three-dimensional shape of the object, and this distortion is used to calculate its geometry.
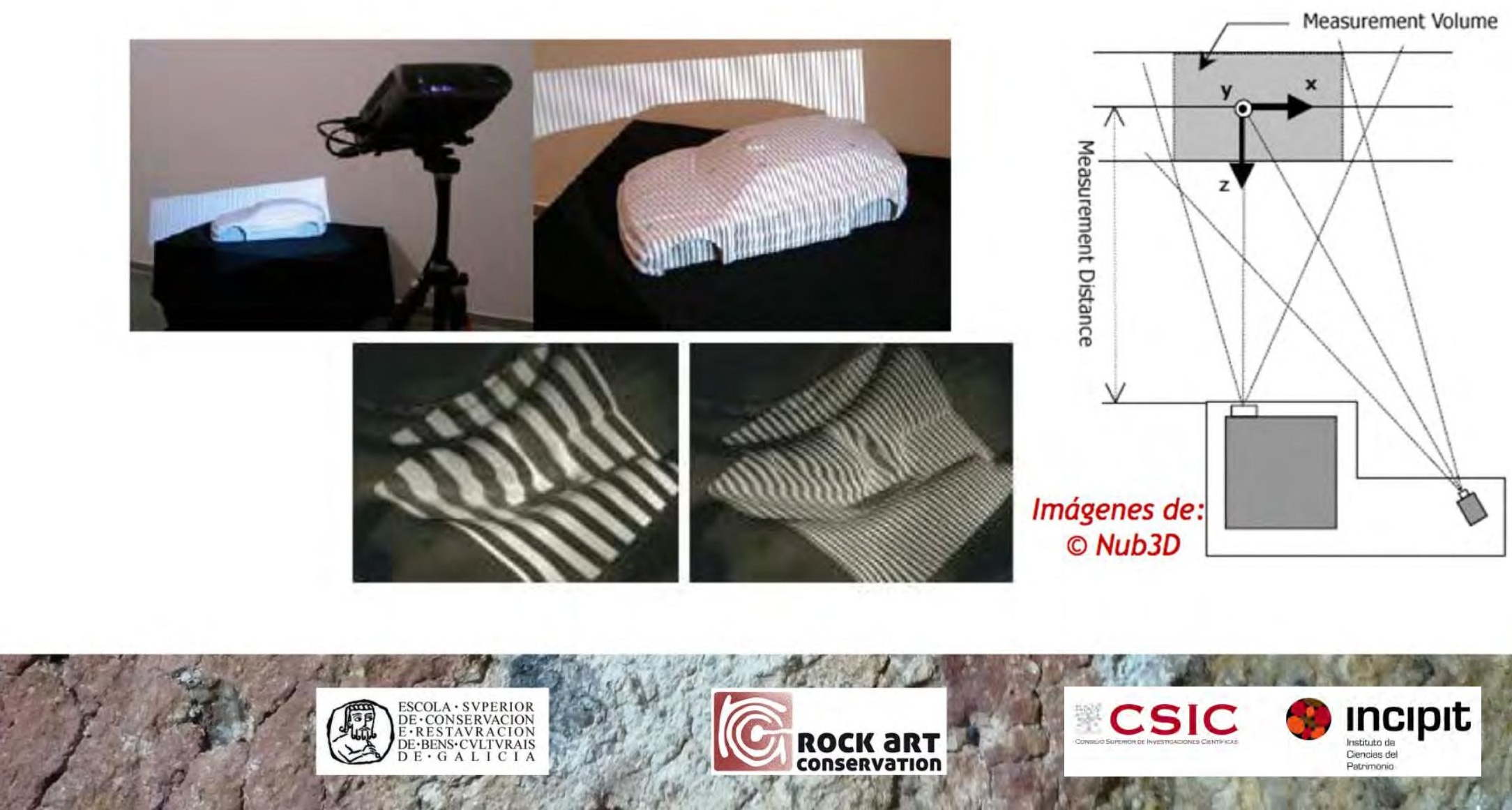

CSIC

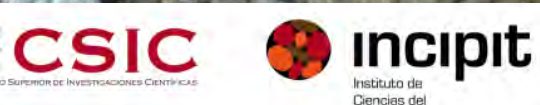

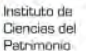


Structured-light scanning: Field work process

Acquisition of 3D geometry
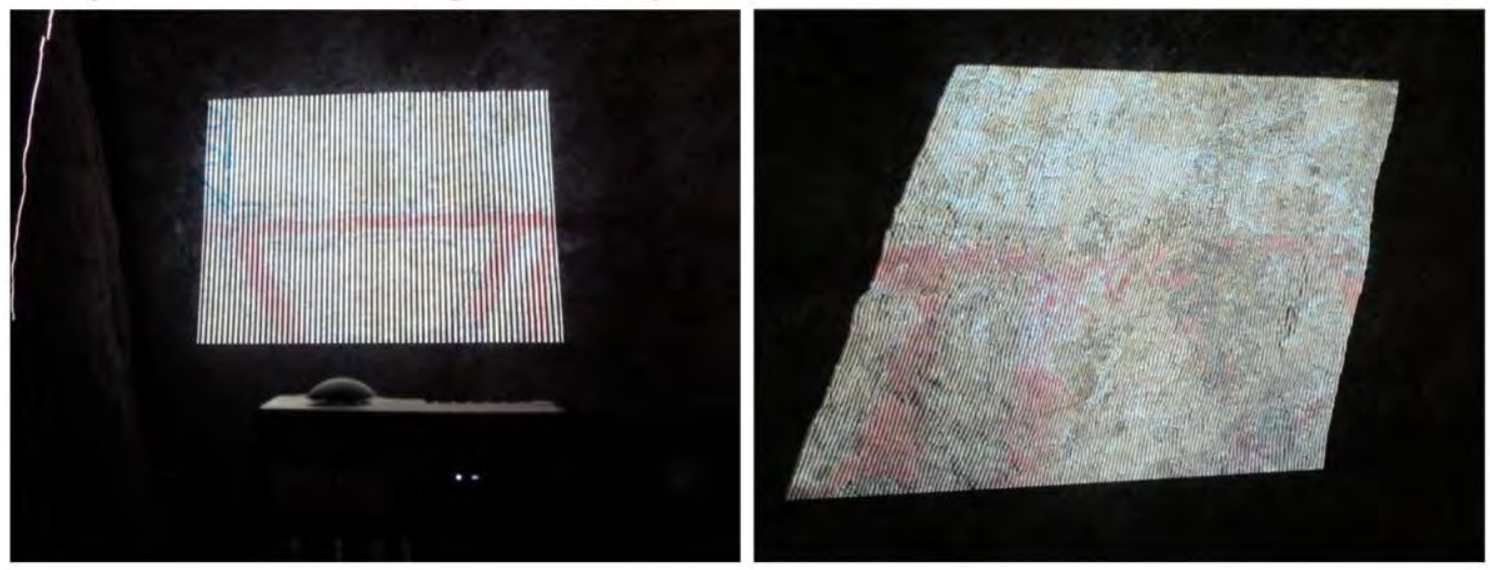

Acquisition of colour
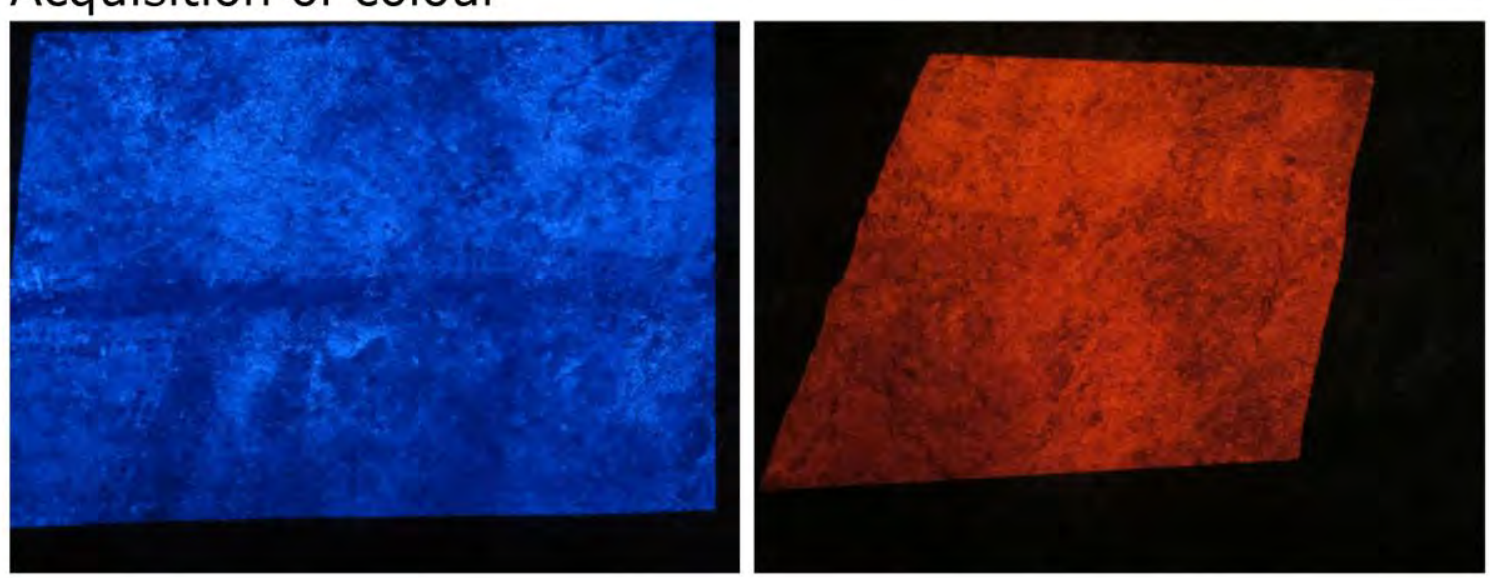

\begin{tabular}{|c|c|c|c|}
\hline ORTHOSTAT & RESOLUTION & $\begin{array}{c}\text { NUMBER } \\
\text { OF SCANS }\end{array}$ & DATE \\
\hline C1 & $0.375 \mathrm{~mm}$ & 25 & $12 / 04 / 2010$ \\
\hline $\mathrm{C} 2$ & $0.375 \mathrm{~mm}$ & 26 & $12 / 04 / 2010$ \\
\hline $\mathrm{C} 3$ & $0.375 \mathrm{~mm}$ & 18 & $12 / 04 / 2010$ \\
\hline C4a & $0.375 \mathrm{~mm}$ & 25 & $13 / 04 / 2010$ \\
\hline C4b & $0.375 \mathrm{~mm}$ & 27 & $13 / 04 / 2010$ \\
\hline C5 & $0.375 \mathrm{~mm}$ & 24 & $12 / 04 / 2010$ \\
\hline C6 & $0.375 \mathrm{~mm}$ & 31 & $13 / 04 / 2010$ \\
\hline C7 & $0.375 \mathrm{~mm}$ & 26 & $14 / 04 / 2010$ \\
\hline L1 & $0.250 \mathrm{~mm}$ & 33 & $15 / 04 / 2010$ \\
\hline L2 & $0.250 \mathrm{~mm}$ & 41 & $16 / 04 / 2010$ \\
\hline L3 & $0.375 \mathrm{~mm}$ & 25 & $14 / 04 / 2010$ \\
\hline R1 & $0.250 \mathrm{~mm}$ & 27 & $16 / 04 / 2010$ \\
\hline R2 & $0.250 \mathrm{~mm}$ & 37 & $15 / 04 / 2010$ \\
\hline R3 & $0.375 \mathrm{~mm}$ & 45 & $14 / 04 / 2010$ \\
\hline
\end{tabular}
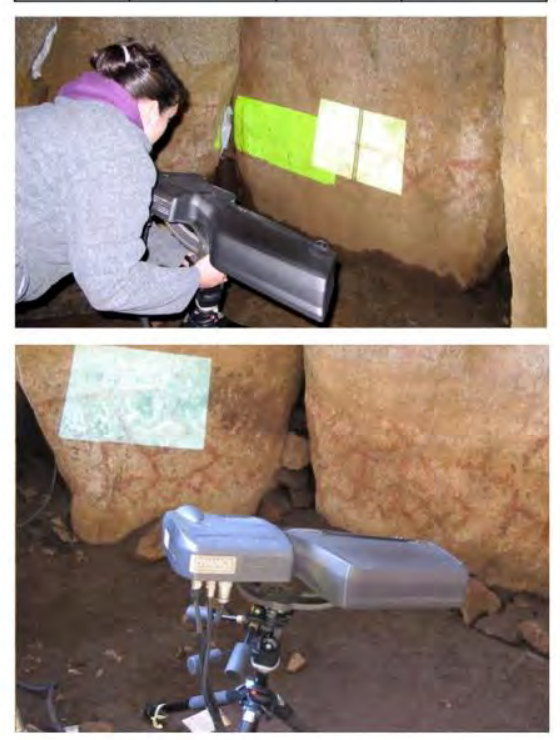

this

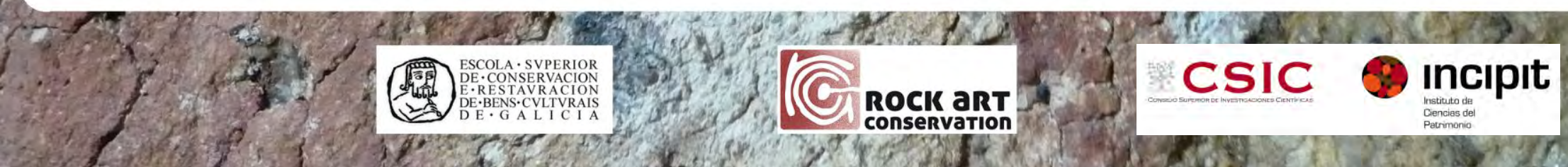


Assembling of individual scans
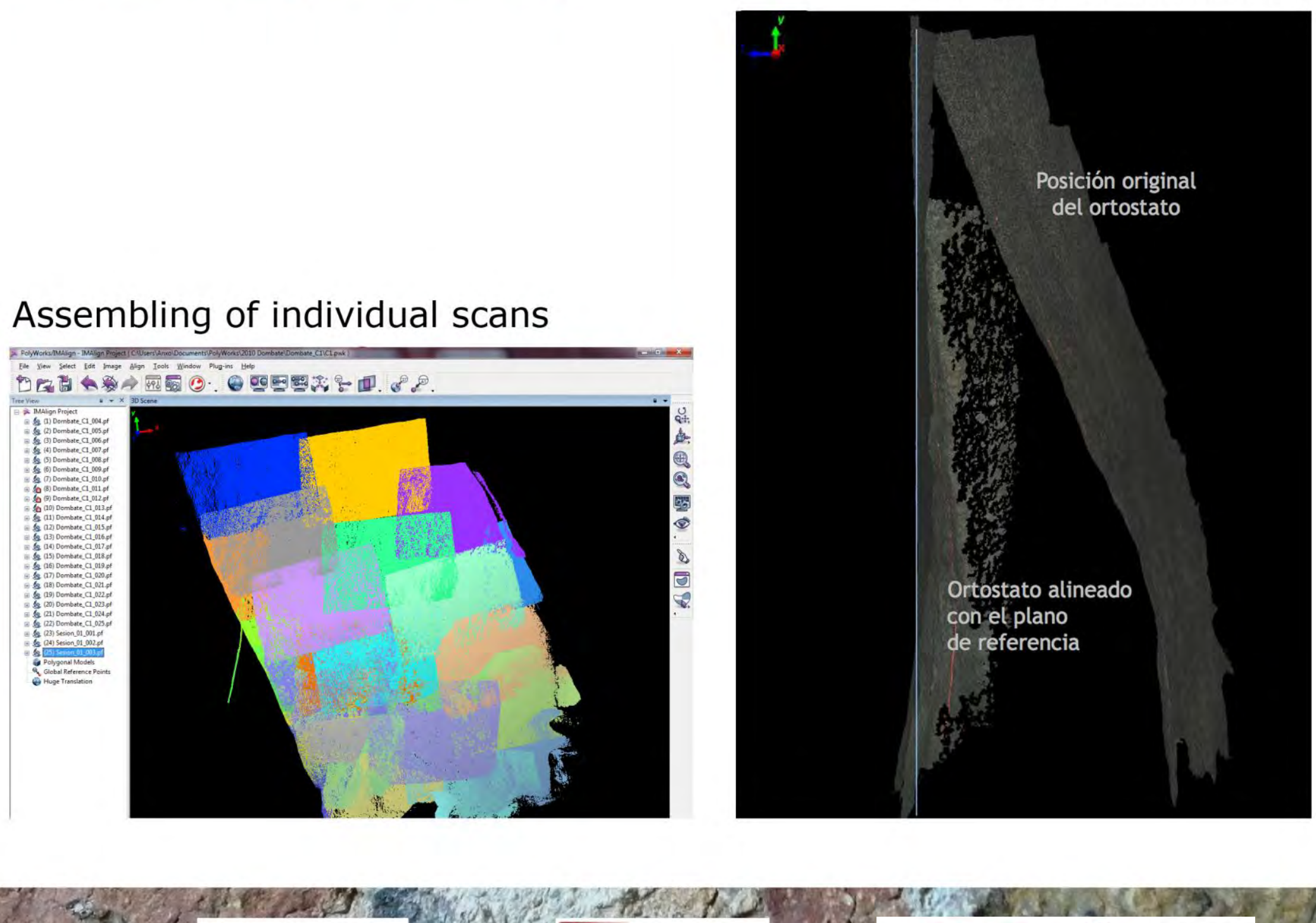
Structured-light scanning: digital illumination of the engravings

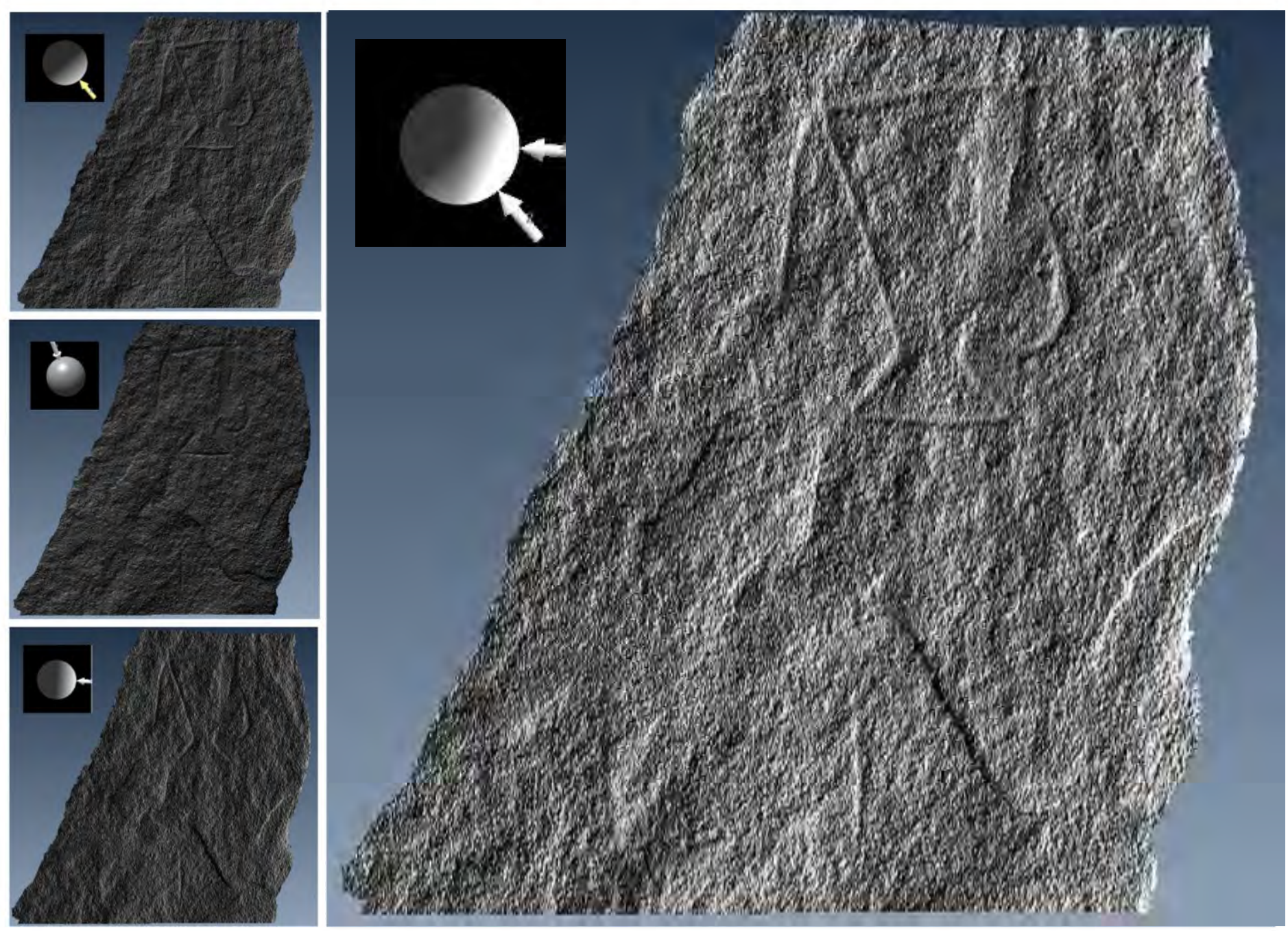

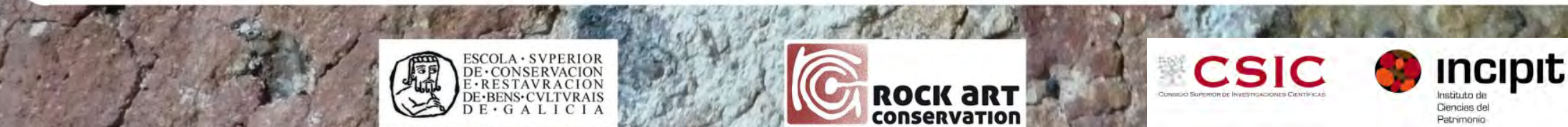

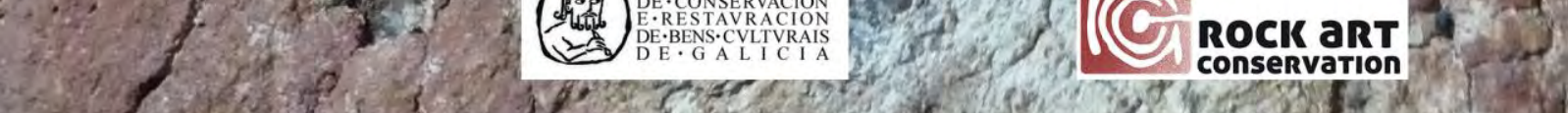


Final tracings

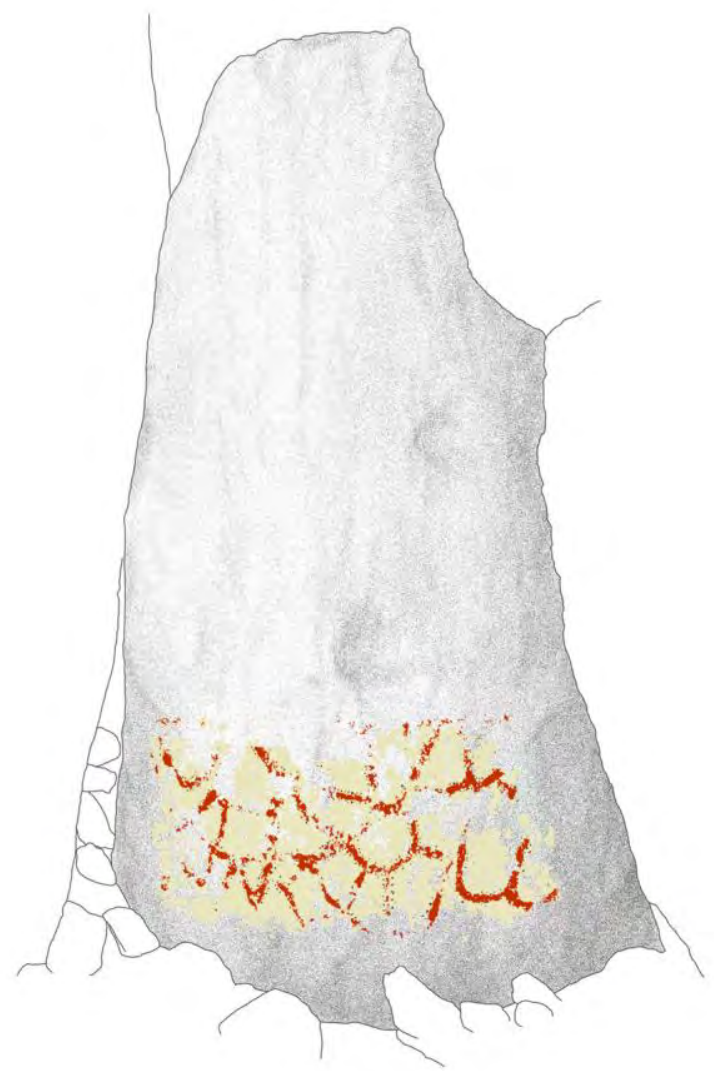

Orthostat C2

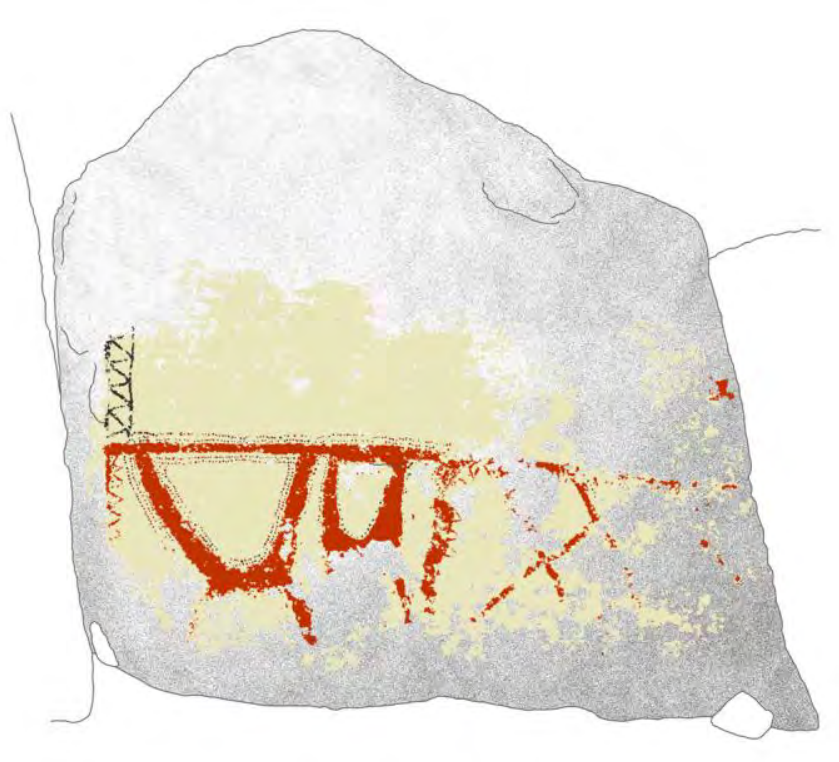

Orthostat R3

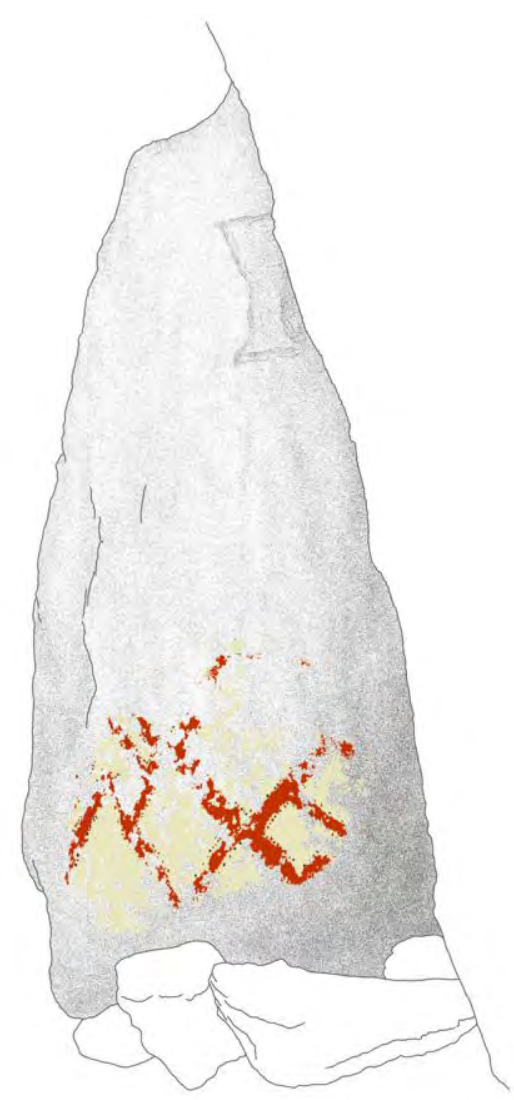

Orthostat C3 
- Indirect (non-invasive) technique

- Geometric technique

- Speed of field data capture

- Simple field work process

- Cost-effective equipment
- Indirect (non-invasive) technique

- Geometric technique

- High accuracy three-dimensional registering technique

- Specific illumination conditions

- High-cost equipment 


\section{Natalia Cortón Noya \\ Rock Art Conservation S.L.}

\section{Fernando Carrera Ramírez}

ESCRBCG Galicia / Rock Art Conservation S.L.

\section{Patricia Mañana-Borrazás}

Instituto de Ciencias del Patrimonio, Consejo Superior de Investigaciones Científicas

\section{Yolanda Seoane-Veiga}

Instituto de Ciencias del Patrimonio, Consejo Superior de Investigaciones Científicas

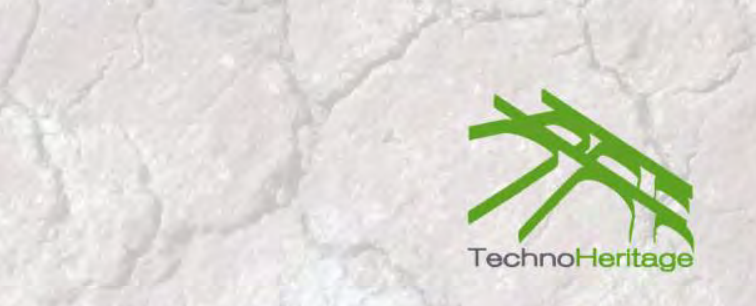

International Congress on

Science and Technology for the Conservation of Cultural Heritage

Por favor, use este identificador para citar o enlazar esta presentación: http://hdl.handle.net/10261/58031

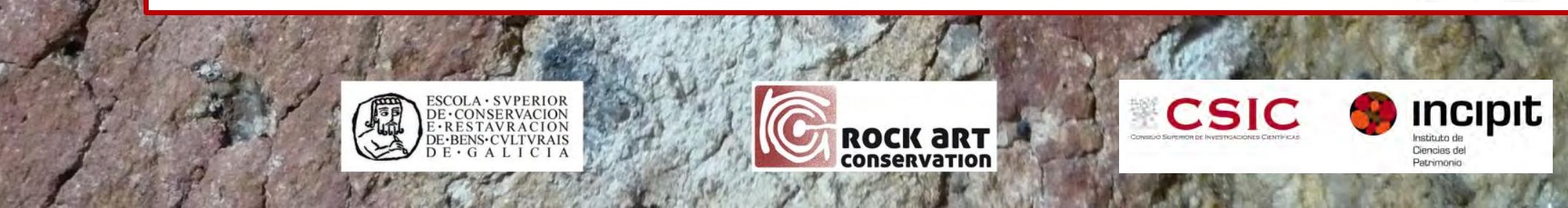

